\title{
THE EFFECT OF GRAMMATICAL ACCURACY AND GENDER ON INTERLANGUAGE REQUEST STRATEGY
}

\author{
I Nyoman Suka Sanjaya \\ (suka.sanjaya@gmail.com) \\ Anak Agung Raka Sitawati \\ (apute@yahoo.com) \\ Politeknik Negeri Bali \\ Jl. Kampus Udayana, Kuta Selatan, Badung, Bali 80361, Indonesia
}

\begin{abstract}
The present study was aimed at examining whether grammatical accuracy and gender were significant predictors of the use of request strategy (direct or indirect). Participants were 39 seventh semester students (29 males and 10 females) majoring in an International Business Management program at a public higher education institution in Bali. Their English proficiency levels ranged from pre-intermediate to intermediate. The participants were asked to write an e-mail based on a situation carefully designed so as to necessitate the use of indirect strategy. Grammatical accuracy was operationalized as an average score per T-unit. The head act of each request was coded as either direct or indirect, and the binary logistic regression was conducted on the data with significance level being set at $\mathrm{p}<.05$. The results revealed that neither grammatical accuracy (Wald $=0.72, d f=1, p=0.40$ ) nor gender (Wald = $0.67, d f=1, p=0.41$ ) was a significant predictor of a request strategy use. The use of request strategy could not also be predicted from the interaction of grammatical accuracy and gender, Wald $=0.66, d f=1, p=0.42$. These results indicate that the odds for using indirect strategy are similar regardless of the level of grammatical accuracy and gender.
\end{abstract}

Keywords: grammatical accuracy, interlanguage request strategy, gender

DOI: http://dx.doi.org/10.15639/teflinjournal.v28i2/212-235 
Pragmatic competence can be defined as the ability to use language appropriately and effectively in a particular context (Timpe Laughlin, Wain, \& Schmidgall, 2015). An EFL (English as a foreign language) learner can be considered pragmatically competent in English if he or she has the knowledge of linguistic resources available in English that can be used to decode and encode a particular illocutionary intent, as well as knowledge of sociocultural conventions pertaining to the appropriate use of those linguistic resources (Roever, 2011, p. 471). These two distinct, yet seemingly interrelated knowledge components making up the concept of pragmatic competence, namely linguistic and sociocultural knowledge, are referred to as the pragmalinguistic and sociopragmatic knowledge, respectively. According to Leech (1983), who first brought the notions of pragmalinguistics and sociopragmatics to the fore, pragmalinguistics refers to "the linguistic end of pragmatics" (p. 11), while sociopragmatics is the "sociological interface of pragmatics" (p. 10). For more recent discussion of pragmalinguistics and sociopragmatics, see Rose (2013) and Takahashi (2013). Compared to other aspects of communicative competence (see Celce-Murcia, 2007), a pragmatic competence constitutes the most important aspect, since the inappropriate use of language can potentially lead to unfortunate, or even dire, consequences (Leech, 2014; Murray, 2010).

Research into interlanguage pragmatics has predominantly focused on speech acts, and requests have become the most researched speech event (Bardovi-Harlig, 2010). This may be triggered by the fact that the enlisting assistance from others is "one of the most basic and ubiquitous activities in social interaction" (Drew \& Couper-Kuhlen, 2014, p. 1), and consequently, the mastery of such speech act by EFL learners seems inevitable. Unfortunately, the majority of those studies have focused on oral mode (Bardovi-Harlig, 2010; Cohen, 2010), leaving the written mode relatively underexplored. Indeed, a number of studies have been carried out to examine learners' pragmatic ability in composing e-mail requests. However, such studies have largely been descriptive and comparative in nature, merely describing the strategies and modification used by the learners, and subsequently comparing them with those used by native speakers (Economidou-Kogetsidis, 2011; Félix-Brasdefer, 2012; Soler, 2013; Szczepaniak-Kozak, 2016; Woodfield, 2015; Zhu, 2012), or describing the cognitive process involved while learners are writing an e-mail (Chen, 2015a). However, classroom experimental research by and large has examined the efficacy of instruction on the acquisition of pragmatic ability in 
writing e-mails (Chen, 2015b, 2016; Nguyen, Do, Nguyen, \& Pham, 2015; Soler, 2015).

The issue of whether grammatical competence can have a significant influence on pragmatic competence has not generated serious attention from researchers (Kecskes, 2014), despite its importance in the field of interlanguage pragmatics (Bardovi-Harlig, 2012). Studies on the effects of grammatical accuracy on interlanguage request strategy use are particularly lacking. It is also true of studies on the effects of gender on request strategy use. Following King and Holmes (2014, p. 1), "gender as a variable has been relatively neglected" in first language pragmatics research, let alone in interlanguage pragmatics research. Consequently, to what extent learners with higher grammatical accuracy tend to use a request strategy different than that used by learners with lower grammatical accuracy still constitutes a mystery. Likewise, the issue of whether learners from a particular gender tend to use a particular request strategy that is different from that used by learners from the opposite gender is also unknown.

The present study attempted to address the above-mentioned lacunas by examining the effects of learners' level of grammatical accuracy and gender on their use of request strategy. The main purpose of the study was twofold: (i) to examine whether level of grammatical accuracy was a significant predictor of request strategy use, and (ii) to examine whether gender was a significant predictor of request strategy use. To be more exact, the study was conducted to specifically delve into the extent to which learners with higher level of grammatical accuracy and from a particular gender used indirect strategy. The present study was an attempt to investigate whether grammatical ability and gender were significant predictors of pragmatic ability.

Schauer (2009) discovered that in response to the same situation nine study abroad (SA) learners used different request strategies. Based on this finding, Schauer (2009) argued that "individual learner differences seem to play an important role in SA learners' use of request strategies" (p. 125). The present study was aimed at examining the extent to which two individual learner differences, knowledge of second language (L2) grammatical accuracy and gender, could influence use of L2 request strategy, an issue that has to date escaped previous researchers' attention.

The present study was conducted within two different theoretical frameworks: relationship between pragmatics and grammar, and relationship between pragmatics and gender. Pragmatic and grammatical competence are integral components of the communicative competence concept (Celce-Murcia, 
2007; Timpe Laughlin et al., 2015). Effective communication necessitates that language users acquire the two types of ability that seem to be interrelated to one another. That is, to be able to use language appropriately may require a sufficient level of grammatical knowledge. It would be impossible for a learner to say I was wondering if you could lend me IDR 100,000 without a sufficient level of grammatical knowledge. Thus, intuitively speaking, increased grammatical knowledge might be accompanied by similarly increased pragmatic knowledge. This is, in fact, the argument put forth by some of the researchers working within the field of interlanguage pragmatics (see Kasper \& Rose, 2002; Kecskes, 2014). The present study was aimed at further exploring if this line of argumentation was indeed empirically valid. Research into gender and discourse suggests that females are more tactful than males in their discursive practice. Extrapolating from such research, it could be argued that female learners' language use might be more appropriate compared to that produced by their male counterparts. In a nutshell, the present study was driven by the following three research questions:

1. Can request strategy use be significantly predicted by grammatical accuracy? That is, do learners having higher grammatical accuracy tend to use indirect request strategy compared to those with lower grammatical accuracy in a situation wherein indirect strategy is the norm?

2. Can request strategy use be significantly predicted by gender? That is, do female learners tend to use indirect request strategy compared to male learners in a situation wherein indirect strategy is the norm?

3. Can request strategy use be significantly predicted by the interaction between grammatical accuracy and gender? That is, do female learners having higher grammatical accuracy tend to use indirect strategy compared to male learners with lower grammatical accuracy in a situation wherein indirect strategy is the norm?

The present study is of theoretical and pedagogical significance. Theoretically, the findings of the present study will further our understanding of the interrelationship between pragmatic and grammatical competence. In particular, they will shed some light on the critical issue of the effects of grammatical accuracy on the use of request strategy. It has been mentioned above that there is a dearth of evidence showing the relationship between the two components of communicative competence, and evidence indicating whether grammatical accuracy affects pragmatic ability is still relatively unavailable. It also holds true 
of the findings of the effects of gender on request strategy. There has been no study which was specifically designed to examine whether gender could significantly predict the use of request strategy. Pedagogically, the findings of the study can feed into EFL instruction by informing teachers whether it is feasible and effective to teach pragmatics through focus on grammar (see FélixBrasdefer \& Cohen, 2012).

\section{METHOD}

Forty students in the seventh semester (29 females and 11 males), between 21 and 22 years of age, participated in the present study. They were enrolled in a four-year undergraduate program in International Business Management in one medium size public higher education institution located in southern Bali. Since they had not taken any standardized English proficiency test, such as TOEFL, IELTS, or TOEIC, it was not possible to determine their formal level of English proficiency. However, according to their English instructor, on the basis of his informal observation of the students' English performance (both oral and written) in class, their English proficiency level ranged from preintermediate to intermediate, with the majority of them falling into the former. At the time the study was conducted in November 2016, the research participants received 150 minutes of English instruction per week. It is important to note that they had not been studying English pragmatics. None of the participants reported to have lived or visited an English speaking country before. They were told that they participated in a study on business e-mail writing. However, the specific aim of the study was not disclosed to them.

The instrument used to gather the data analyzed in the present study took the form of a written test in which the research participants had to write an email in response to a particular situational scenario depicting a workplace business-related communication (see appendix). Since they were majoring in International Business Management, it could be argued that they were fully familiar with the scenario. The scenario was carefully designed so as to elicit the target speech act (i.e. request) and include the following contextual characteristics: (i) the power difference between the e-mail writer (research participant) and the recipient was large whereby the power of the latter was much higher than that of the former; (ii) the social distance between the e-mail writer and recipient was large; and finally, (iii) the request sounded highly impositive. As such, the situation described a condition wherein the FTA (face threatening act) created 
by the request was serious. Such condition, from the perspective of English culture, requires that the request is executed using indirect strategy (Brown \& Levinson, 1987). Finally, the language used to describe the situation was English, but an attempt was made to ensure that the language was easy to understand.

Before the test was administered the participants were informed that the test was a data gathering session, and all of them agreed to participate. The test was a paper-and-pencil test and was not timed. The test was administered strictly to ensure the validity (i.e. independence) of the resulting data. The participants were allowed to ask questions during the test administration as long as those questions were related to the scenario, but not to the English language, such as vocabulary and grammar. In fact, none of the students asked any question, indicating that the language was within their comprehension level and was free from ambiguity. The time needed by the participants to complete the task ranged from 20 minutes to 30 minutes. Upon completion of the test, the participants were subsequently consulted regarding the characteristics of the scenario used in the research instrument. This was done to see the extent to which the participants' perception of the scenario used in the test corroborated that of the researcher. In general, they agreed that the imposition associated with the request was great, that their relationship with the recipient was distant, and that the recipient's power was big relative to theirs.

The present paper presents a multivariate study of the effect of grammatical accuracy and gender (in isolation and in combination) on request strategy use. As such, there were two predictor variables, namely grammatical accuracy (a continuous variable) and gender (a binary dichotomous variable: male or female), and one outcome variable, viz. request strategy (a binary dichotomous variable which was either direct or indirect). The unit of analysis for the predictor variable of grammatical accuracy was T-unit (i.e. minimal terminable unit) defined as "the shortest unit ... which a sentence can be reduced to, and consisting of one main clause with all subordinate clauses attached to it" (Tavakoli, 2012, p. 681). Each of the e-mail requests were broken down into Tunits, and each T-unit was scored following the scoring rubric presented in Table 1 .

Table 1. Scoring Rubric for Grammatical Accuracy

\begin{tabular}{ll}
\hline Score & Remarks \\
\hline 4 & T-Unit contains no grammatical error \\
\hline
\end{tabular}




\begin{tabular}{ll}
\hline Score & Remarks \\
\hline 3 & T-unit contains one grammatical error \\
\hline 2 & T-unit contains two grammatical errors \\
\hline 1 & T-unit contains more than two grammatical errors \\
\hline
\end{tabular}

Segmentation of the e-mails into their T-units did not include the salutation (e.g. Dear Mr. Blunder), and hence they were not assigned any accuracy score. It could be argued that through the use of such salutation, students did not necessarily demonstrate their knowledge of grammatical accuracy. It should be stressed that grammatical errors analyzed in the present study included not only syntactic errors (e.g. Tomorrow I am have a job to send a parcel ...), but also morphological ones (e.g. I can driving). Other errors (e.g. spelling errors, punctuation errors) were excluded from the analysis, since those errors cannot be regarded as having anything to do with grammatical accuracy. Grammatical accuracy score for one e-mail was computed by averaging the scores of all T-units making up the e-mail in question. The second predictor variable, gender, is obviously self-explanatory, and hence no explanation is necessary here.

The unit of analysis for the outcome variable (i.e. request strategy) was the individual e-mail. The definition of request strategy adopted in the present study is as follows: "the communicative means we use when trying to get someone to do something they would probably not do of their own accord" (Leech, 2014, p. 143). Since request strategy resides in the head act of a request, each e-mail was first independently segmented to delimit the request head act, defined as that segment of the e-mail "that constitutes the nucleus of the speech act ... i.e. that part of the sequence which might serve to realize the act independently of other elements" (Blum-Kulka \& Olshtain, 1984, p. 201). The request strategy of the head act contained in each e-mail was then coded in terms of its level of directness, as either direct or indirect, based on the framework deployed in the study conducted by Blum-Kulka and Olshtain (1984). It is to be borne in mind that the analytical framework used by Blum-Kulka and Olshtain (1984) comprised of three types of request strategy, viz. direct, conventionally indirect, and hints. In the present study, conventionally indirect strategy and hint, following their practice, were grouped into indirect strategy. What follows is the request strategy coding scheme used in the present study (examples were taken from data of the present study). 
Sanjaya \& Sitawati, Interlanguage Request Strategy 219

Table 2. Request Strategy Coding Scheme

\begin{tabular}{cll}
\hline Strategy & Description & Example \\
\hline A. Direct & & \\
\hline Want & $\begin{array}{l}\text { The writer explicitly expresses } \\
\text { his or her request through want } \text { or } \\
\text { would like }\end{array}$ & $\begin{array}{l}\text { We would like to borrow your } \\
\text { car which is available in our } \\
\text { company }\end{array}$ \\
\hline Need & $\begin{array}{l}\text { The writer expresses his desire to } \\
\text { make a request through need }\end{array}$ & $\begin{array}{l}\text { I need to borrow one of your } \\
\text { car? }\end{array}$ \\
\hline Performative & $\begin{array}{l}\text { The communicative intent is } \\
\text { marked explicitly through a } \\
\text { performative verb. }\end{array}$ & $\begin{array}{l}\text { My aim in writing this e-mail is } \\
\text { to ask permission to use your } \\
\text { car }\end{array}$ \\
\hline B. Indirect & & \\
\hline Preparatory & $\begin{array}{l}\text { The communicative intent is } \\
\text { conventionally expressed through } \\
\text { a preparatory condition. }\end{array}$ & May I borrow your car? \\
\hline Hint & $\begin{array}{l}\text { The communicative intent is } \\
\text { indirectly stated through a hint. }\end{array}$ & $\begin{array}{l}\text { I hope you can help me to } \\
\text { provide a car. }\end{array}$ \\
\hline
\end{tabular}

To answer the research questions mentioned earlier, the data were statistically analyzed using binary logistic regression, with the significance level $(p)$ being set at $p<.05$. Binary logistic regression is used when the outcome variable is dichotomous (i.e. has only two categories) and the predictor variable can be either interval or categorical, or both (Hahs-Vaughn, 2017, pp. 117-168). All statistical analyses were conducted with the help of SPSS (Statistical Package for the Social Sciences) version 23.

\section{FINDINGS AND DISCUSSION}

Table 3 below shows the descriptive statistics of grammatical accuracy scores. It should be reiterated that the lowest score that a participant could obtain was 1 , while the highest (i.e. perfect) score was 4.0. It was found that the minimum score was 1.7 and obtained by only one participant $(2.5 \%$ of the total participants), whereas the perfect score was obtained by three participants ( $7.5 \%$ of the total participants). In fact, 1.7 was an outlier, that is a value very different from other values in the present study (Field, 2009). Therefore, it would seem reasonable to argue that the participant with the accuracy score of 1.7 was exceptionally poor in his or her knowledge of grammatical accuracy relative to other participants in the present study. With an average score of 3.31 
(out of the highest average score of 4.0), it could be argued that the participants in the present study were relatively grammatically competent, as far as grammatical accuracy was concerned. The magnitude of the standard deviation $(0.45)$ relative to the mean value of 3.31 strongly indicated that the mean was a good fit to the observed data. To put it in less technical terms, the mean value represented all the values observed in the data set. The relatively small standard deviation value indicated that the participants in the present study were uniform in terms of their knowledge of grammatical accuracy. That is, on average, each participant's score deviated from the sample mean by less than half a point. Finally, the relatively small size of the standard error of the mean suggested that the sample of the present study could be considered as defensibly representative of the target population (i.e. English language learners studying in a foreign language learning context). A standard error of 0.71 shows that if we drew infinite samples from the population from which the sample of the present study came, on average the mean of each of those infinite samples would differ from the mean of the entire population by only 0.71 .

Table 3. Descriptive Statistics for Grammatical Accuracy Score

\begin{tabular}{|c|c|c|c|c|c|c|}
\hline \multirow{3}{*}{$\begin{array}{l}\text { Grammatical } \\
\text { Accuracy }\end{array}$} & \multirow{2}{*}{$\mathbf{N}$} & \multirow{2}{*}{ Minimum } & \multirow{2}{*}{ Maximum } & \multicolumn{2}{|c|}{ Mean } & \multirow{2}{*}{$\begin{array}{c}\text { Std. } \\
\text { Deviation }\end{array}$} \\
\hline & & & & Statistic & Std. Error & \\
\hline & 40 & 1.70 & 4.00 & 3.31 & 0.71 & 0.45 \\
\hline
\end{tabular}

Several e-mails contained more than one request, one of which served as the main request (i.e. request to borrow the car) while the other was a secondary one (e.g. request to get a prompt reply). For example, the following two requests were identified in the same e-mail: I would like to ask your permission to allow me to use your car to send the parcel and Please reply my e-mail as soon as possible. In this particular instance, only the former is clearly a request to borrow the car. The practice adopted in the present study, due to the nature of the statistical procedure followed, was that only the main request was included in the analysis. It is to be borne in mind that one of the aims of the present study was to examine whether knowledge of grammatical accuracy could significantly predict request strategy use (direct or indirect). Thus, including all request strategies identified in an e-mail would not achieve the aim, since two or more request strategies used in an e-mail could belong to both strategies (direct and indirect). Table 4 below shows all participants' frequency of use of the two types of request strategy. 
Table 4. Frequency of Major Request Strategy Types

\begin{tabular}{ccccccc}
\hline \multirow{2}{*}{ Request Strategy } & \multicolumn{2}{c}{ Direct } & \multicolumn{2}{c}{ Indirect } & \multicolumn{2}{c}{ Total } \\
\cline { 2 - 7 } & $\mathrm{n}$ & $\%$ & $\mathrm{n}$ & $\%$ & $\mathrm{~N}$ & $\%$ \\
\cline { 2 - 7 } & 20 & 50 & 20 & 50 & 40 & 100 \\
\hline
\end{tabular}

As can be seen from Table 4 above, the number of participants (male and female combined) who preferred to use indirect strategy was similar to the number of participants who preferred to use direct strategy.

Table 5 below presents the frequency of use of sub-strategies (want, need, performative, preparatory, and hint) within each of the two major strategies (direct and indirect).

Table 5. Frequency of Use of Sub-strategies

\begin{tabular}{lcc}
\hline Request Strategies & $\mathbf{n}$ & $\mathbf{\%}$ \\
\hline Direct & 20 & 50 \\
\hline Want & 10 & 25 \\
\hline Need & 7 & 17.5 \\
\hline Performative & 3 & 7.5 \\
\hline Indirect & 20 & 50 \\
\hline Preparatory & 18 & 45 \\
\hline Hint & 2 & 5 \\
\hline Total & 40 & 100 \\
\hline
\end{tabular}

Within the major category of direct strategy, the sub-strategy want was the most preferred $(50 \%, \mathrm{n}=10)$, followed by need $(35 \%, \mathrm{n}=7)$ and performative $(15 \%, \mathrm{n}=3)$. Within the category of indirect strategy, the sub-strategy preparatory predominated $(90 \%, \mathrm{n}=18)$, while the sub-strategy hint was used with much smaller frequency $(10 \%, \mathrm{n}=2)$.

Table 6 shows the frequency of use of the two major request strategies (direct and indirect) by the two gender groups. As vividly shown by the table, indirect strategy was employed more frequently than direct strategy by female learners, $40 \%(\mathrm{n}=16)$ versus $32 \%(\mathrm{n}=13)$, respectively. By contrast, male learners employed direct strategy with greater frequency than indirect strategy, $17.5 \%(n=7)$ versus $10 \%(n=4)$, respectively.

\section{Table 6. Use of Request Strategies by the Two Gender Groups}

\begin{tabular}{lcccc}
\hline & & \multicolumn{2}{c}{ Gender } & \multirow{2}{*}{ Total } \\
\cline { 2 - 4 } & & Female & Male & \\
\hline Request Strategy & Direct & 13 & 7 & 20 \\
\cline { 2 - 4 }
\end{tabular}




\begin{tabular}{llccc}
\hline & & \multicolumn{2}{c}{ Gender } & \multirow{2}{*}{ Total } \\
\cline { 2 - 4 } & & Female & Male & \\
\cline { 2 - 5 } & $(\%)$ & $(32.5 \%)$ & $(17.5 \%)$ & $(50 \%)$ \\
\cline { 2 - 5 } & Indirect & 16 & 4 & 20 \\
\hline Total & & $(40 \%)$ & $(10 \%)$ & $(50 \%)$ \\
\hline$(\%)$ & & $(72.5 \%)$ & $(27.5 \%)$ & $(100 \%)$ \\
\hline
\end{tabular}

Table 7 displays the frequency of use of the five sub-strategies by the two gender groups. Female learners used preparatory sub-strategy most frequently $(\mathrm{n}=14)$, followed by want sub-strategy $(\mathrm{n}=7)$. Need and performative substrategies were used with similar frequency $(\mathrm{n}=3)$. Finally, hint sub-strategy was the least preferred sub-strategy within female gender group. Within male gender group, the picture was quite different. The frequencies of use of the substrategies were virtually identical, except that two sub-strategies were not at all used (performative and hint).

Table 7. Frequency of Use of Sub-strategies within the Two Gender Groups.

\begin{tabular}{lllccccc}
\hline & & \multicolumn{4}{c}{ Gender } & \multicolumn{2}{c}{ Total } \\
\cline { 3 - 8 } & & \multicolumn{2}{c}{ Female } & \multicolumn{2}{c}{ Male } & \multicolumn{2}{c}{ To/ } \\
\cline { 2 - 8 } & & $\mathbf{n}$ & $\mathbf{\%}$ & $\mathbf{N}$ & $\mathbf{\%}$ & $\mathbf{n}$ & $\mathbf{\%}$ \\
\hline \multirow{3}{*}{ Request sub-strategies } & Want & 7 & 17.5 & 3 & 7.5 & 10 & 25 \\
\cline { 2 - 8 } & Need & 3 & 7.5 & 4 & 10 & 7 & 17.5 \\
\cline { 2 - 8 } & Performative & 3 & 7.5 & 0 & 0 & 3 & 7.5 \\
\cline { 2 - 8 } & Preparatory & 14 & 35 & 4 & 10 & 18 & 45 \\
\cline { 2 - 8 } & Hint & 2 & 5 & 0 & 0 & 2 & 5 \\
\hline Total & & 29 & 72.5 & 11 & 27.5 & 40 & 100 \\
\hline
\end{tabular}

Tests of assumptions of logistic regression were conducted to examine whether the data met those assumptions. This stage is necessary to arrive at valid statistical results; data set not meeting the assumptions of the inferential statistic employed would produce biased results. The results showed evidence of noncollinearity ${ }^{1}$, as indicated by a tolerance value of 0.95 and a VIF (Variance In-

\footnotetext{
${ }^{1}$ Noncollinearity refers to the condition where "the predictor variables are not highly correlated", and such condition is desired in multiple regression (Hahs-Vaughn, 2017, p. 290).

${ }^{2}$ Multicollinearity is the opposite of noncollinearity, that is a condition where the
} 
flation Factor) value of 1.06. Tolerance value less than 0.10 and VIF value greater than 10 indicate multicollinearity ${ }^{2}$ (Hahs-Vaughn, 2017, p. 151). Thus, the assumption of noncollinearity was met in the present study. The assumption of linearity was also met, as shown by the statistically non-significance of the interaction term of the continuous variable (i.e. grammatical accuracy) and its natural $\log , B=-0.36, S E=0.44$, Wald $=0.69, d f=1, p=0.41$. Non-existence of linearity is indicated by significant interaction, as shown by the value of $p$ which is greater than .05 . The assumption of independence of errors was also met in the present study. Field (2009) states that independence of errors "means that cases of data should not be related; for example, you cannot measure the same people at different points in time" (p. 273). In the present study, no two cases were related to each other since none of the participants were asked to write an e-mail more than once.

It is worth reiterating here that the inferential statistic employed to analyze the data in the present study was binary logistic regression. Such statistic enables us to predict the probability that the outcome variable will occur on the basis of knowledge of the predictor variable(s). In the present study, using binary logistic regression knowledge of grammatical accuracy and gender (predictor variables) allowed us to predict the probability that either direct or indirect request strategy (outcome variable) would occur. To put it in different terms, using binary logistic regression allowed us to determine whether grammatical accuracy and gender, as well as their interaction, could significantly influence the use of request strategy.

The baseline logistic regression model (i.e. the model that resulted from including only the constant) generated by SPSS to best fit the observed data in the present study predicted that all participants, regardless of their level of grammatical accuracy and gender, used indirect strategy and, as can be expected, such model correctly classified $50 \%$ of all participants, but misclassified the other $50 \%$. This baseline model did not include the predictor variables (grammatical accuracy and gender). As the name suggests, it was used as the yardstick against which the new model having the predictor variables was assessed. That is, if the new model has statistically significant greater classification accuracy and statistically smaller -2Log-likelihood values than the baseline

\footnotetext{
${ }^{2}$ Multicollinearity is the opposite of noncollinearity, that is a condition where the predictor variables are highly correlated, and it is required that such condition does not occur in multiple regression (Hahs-Vaughn, 2017, p. 290).
} 
model, then the predictor variables (either in isolation or combination) can be said to have a significant effect on the outcome variable.

The -2Log-likelihood of the baseline model was 55.45. The statistical result also revealed that the coefficients for the covariates (i.e. predictor variables) not included in the baseline model (i.e. grammatical accuracy and gender) were not different from zero, as shown by the value of the residual chi-square statistic, $\chi^{2}=3.53, d f=3, p=0.32$. This means that the addition of the predictor variables to the regression model would not make any difference. That is, it would not significantly contribute to (i.e. improve) the predictive power of the baseline model, which means that the predictor variables in the present study had zero effect on the use of request strategy. In other words, the two predictor variables did not have any predictive power regarding the use of request strategy. Less technically speaking, it indicated that the two predictor variables were not powerful enough to influence the use of request strategy. Indeed, the addition of the predictor variables to the baseline model did result in improved classification accuracy of the new model $(62.5 \%)$, compared to that before the predictor variables were added to the model $(50 \%)$. Yet, such improvement in classification accuracy was not statistically significant. This showed, again, that the predictor variables in the present study had an insignificant influence on the use of request strategy.

The above results were confirmed by the overall fit of the new model (i.e. when the predictor variables were included): $-2 \log$ likelihood $=51.59$, Cox and Snell $\mathrm{R}^{2}=0.09$; Nagelkerke $\mathrm{R}^{2}=0.12$. Although the $-2 \mathrm{Log}$ likelihood value of the new model was less than that of the baseline model, which was, as stated earlier, a good thing (see Field, 2009, p. 285), such improvement was not sufficient to reach statistical significance. Note also the small effect size of the new model which ranged from $9 \%$ to $12 \%$. This strongly indicated that the two predictor variables had negligible effect on the probability of the indirect strategy being used. The effect sizes showed that the influence of the two predictor variables on the use of request strategy ranged from $9 \%$ to $12 \%$ only, whereas the remaining proportions of influence (between $82 \%$ and $91 \%$ ) came from other factors not investigated in the present study. In short, grammatical accuracy and gender did not seem to significantly predict whether indirect strategy was deployed in situation where such strategy was necessary.

Table 8 provides further confirmation of the non-significant contribution of the predictor variables in the present study (grammatical accuracy and gender, as well as their interaction) to the probability of indirect strategy being 
used. Table 8 shows that every one-unit increase in grammatical accuracy would result in a decrease in the logit (i.e. natural logarithm) of indirect strategy by 1.27 unit. Again, this indicated that knowledge of grammatical accuracy was not a significant predictor of use of indirect strategy in situation where such strategy was necessary. In fact, knowledge of grammatical accuracy brought about an adverse impact on the use of indirect strategy (Notice in Table 8 the negative association between grammatical accuracy and use of indirect strategy). The table also shows that the odds of a learner with a higher knowledge of grammatical accuracy using indirect strategy were 28\% $(0.28$ times) lower than those of a learner with lower knowledge of grammatical accuracy. The same can also be said of the predictor variable gender. There was no association evident between gender and the probability of indirect strategy being used in situation where such strategy was necessary. The odds of a female learner using indirect strategy in the situation wherein such strategy was necessary were exactly the same as those of a male learner (see Exp(B) value for gender in Table 8). A chi-square test was also run on the data to examine whether female learners were more likely to use indirect strategy than male learners. The result was not significant, $\chi^{2}=1.13, d f=1, p=0.29$, meaning that female learners were not more likely to use indirect strategy in situation wherein such strategy was the norm. This finding showed that gender did not have any effect on the use of request strategy. Interestingly, it was found that the odds of a male learner with higher grammatical accuracy using indirect strategy were $1,804 \%$ (or 18.04 times) higher than those of a female learner with lower grammatical accuracy knowledge. Unfortunately, this statistical result was also not significant at $p<.05$, meaning that male learners with higher grammatical accuracy were not significantly more likely to use indirect strategy compared to those female learners with lower grammatical accuracy.

Table 8. Variables in the Equation

\begin{tabular}{|c|c|c|c|c|c|c|c|c|c|}
\hline & & \multirow[t]{2}{*}{ B } & \multirow[t]{2}{*}{ SE } & \multirow[t]{2}{*}{ Wald } & \multirow[t]{2}{*}{ df } & \multirow[t]{2}{*}{ Sig. } & \multirow[t]{2}{*}{$\operatorname{Exp}(B)$} & \multicolumn{2}{|c|}{$\begin{array}{c}\text { 95\%C.I. for } \\
\text { EXP(B) } \\
\end{array}$} \\
\hline & & & & & & & & Lower & Upper \\
\hline \multirow[t]{3}{*}{ Step } & $\begin{array}{l}\text { Grammatical } \\
\text { Accuracy }\end{array}$ & -1.27 & 1.05 & 1.47 & 1 & .23 & .28 & .04 & 2.19 \\
\hline & Gender & -10.28 & 6.98 & 2.17 & 1 & .14 & .00 & .00 & 29.70 \\
\hline & $\begin{array}{l}\text { Grammatical } \\
\text { Accuracy by }\end{array}$ & 2.89 & 2.09 & 1.91 & 1 & .17 & 18.04 & .30 & 1087.31 \\
\hline
\end{tabular}




\begin{tabular}{lccccccc}
\hline & B & SE & Wald & df & Sig. & $\operatorname{Exp(B)}$ & $\begin{array}{c}\text { 95\%C.I. for } \\
\text { EXP(B) }\end{array}$ \\
\hline Gender & & & & & & & \\
\hline Constant & 4.49 & 3.57 & 1.58 & 1 & .21 & 89.25 & \\
\hline
\end{tabular}

To return to our research questions, on the basis of the data obtained in the present study presented above, we can conclude that: (i) knowledge of grammatical accuracy was not a significant predictor of request strategy use, in the sense that a learner with higher grammatical accuracy knowledge would not use indirect request strategy in situation wherein such strategy was necessary, compared to those with lower grammatical accuracy knowledge; (ii) gender was not a significant predictor of request strategy use, in the sense that a female learner would not use indirect request strategy in situation wherein such strategy was necessary, compared to a male learner; and (iii) interaction between knowledge of grammatical accuracy and gender was not a significant predictor of request strategy use, in the sense that a female learner with higher grammatical accuracy knowledge would not use indirect request strategy in a situation wherein such strategy is necessary, compared to a male learner with lower grammatical accuracy knowledge.

The finding of the present study strongly suggests that the development of pragmatic competence does not require prior development of grammatical competence, and as such, it is consistent with the finding of a three-year longitudinal case study conducted by Schmidt (1983). Wes, a participant in Schmidt's study, displayed an impressive development in his ability to use English appropriately, or in other words, his pragmatic ability developed significantly during his three-year stay in Hawai'i. At the other extreme, his grammatical proficiency showed stagnation, meaning that it remained rudimentary. The present study also provides important empirical evidence in support of the contention made by Bardovi-Harlig (2001, p. 14) that "a learner of high grammatical proficiency will not necessarily possess concomitant pragmatic competence." However, the finding of the present study contradicts that of a study carried out by Celaya and Barón (2015). In Celaya and Barón's study, learners with higher grammatical level were found to use more indirect strategies compared to those with lower grammatical level. There are at least two factors which may account for such contradiction. First, the way the concept of 'grammatical competence' was operationalized in the present study was differ- 
ent from that in Celaya and Barón's study. In the present study, it was confined to only grammatical accuracy, whereas in Celaya and Barón's study it included not only grammatical accuracy, but also grammatical complexity. To put it in different terms, grammatical competence in the present study was defined more narrowly than in Celaya and Barón's study. Second, the size and characteristics of the participants involved in the two studies were different. The present study involved fewer participants than Celaya and Barón's study, 40 versus 144, respectively. In the present study the participants were uniform in terms of their ages, whereas in Celaya and Barón's study the participants were between the ages of 10 and 18 .

The findings of the present study suggest that it is possible for learners to gain pragmatic competence without gaining grammatical competence first. Admittedly, this seems to be counterintuitive, as some people might believe that "in order to do things with words in a target language, the 'words' - used synecdochically for the grammar - must already be in place" (Kasper \& Rose, 2002 , p. 164). Gaining pragmatic competence without gaining advanced grammatical competence first does not necessarily mean that learners can be pragmatically competent in English even though they have zero mastery of English grammar. Of course, zero mastery of grammar implies that any string of words might be incomprehensible. It is difficult to imagine a situation where a learner with no knowledge of English grammar can make a pragmatically meaningful verbal (i.e. linguistic) expression. That it is possible for learners to gain pragmatic competence without gaining grammatical competence first means that to be pragmatically competent learners do not need to wait until their grammatical competence reaches advanced level. Even basic or rudimentary grammatical proficiency can do the job quite well when it comes to using language according to social norms or conventions. Wes in the aforementioned Schmidt's (1983) study managed to successfully issue requests (e.g. maybe curtain = maybe you should open the curtain), despite his apparently undeveloped grammatical competence. It is to be noted that all English native speakers with whom he communicated considered him highly pragmatically competent. This may simply be by virtue of the fact that adult second language (L2) speakers may not need to resort to their knowledge of grammar when they need to convey an illocutionary intent. Rather, they make use of their first language pragmatic competence. As astutely argued by Kecskes (2015), L2 pragmatic skills "appear like modifications, adjustments and additions to the existing L1based pragmatic competence" (p. 421). This may explain why learners in the 
present study were not different in terms of their use of request strategy regardless of the differences in grammatical competence. It may be the case that when responding to the situation given in the present study the learners were drawing upon their Indonesian-based pragmatic competence.

Related to the issue of L2 speakers' not relying on grammar resources when conveying an illocutionary intent is the fact that listeners do not likewise merely rely on grammatical features of utterances to extract the pragmatic meaning embedded in the utterances. Extra-linguistic context may play a more significant role in pragmatic inference. As in the words of King and Holmes (2014, p. 4), "a great deal of pragmatic inference is understood via a combination of language, tone, gesture, gaze, spatial orientation, embodiment, and facial expression as well as myriad other nonverbal means."

The present study produced empirical evidence which suggests that grammatical and pragmatic competence constitute two different things. Following Kecskes (2015, p. 421), "Grammatical competence is about correctness while pragmatic competence is more about appropriateness." The development of grammatical competence does not seem to go hand in hand with that of pragmatic competence for adult L2 learners, accordingly. In particular, it seems that grammatical competence cannot accelerate the development of pragmatic competence, as the two types of competence appear to take different developmental paths. This is because the nature of grammatical development is quite different from that of pragmatic development in adult L2 acquisition (Kecskes, 2015). That grammatical and pragmatic competence are independent of each other is quite surprising given the two types of competence make up the concept of 'communicative competence'. However, it sheds some light on the importance of the two types of competence. It may be that grammatical and pragmatic competence do not carry the same weight when it comes to effective communication. Recall that Wes in Schmidt's (1983) study was considered as an effective communicator by his native speaker interlocutors despite his apparently defective grammatical competence.

Research involving native speakers has discovered that indirect directives index femininity (King \& Holmes, 2014). A study conducted by Jones and Adrefiza (2017) involving Indonesian native speakers discovered that females and males differed from each other in terms of their apologizing behavior in Indonesian. The present study did not produce empirical evidence consistent with that yielded in research involving native speakers; in the present study, female learners were not found to use indirect strategy at significantly greater 
frequency than male ones. Therefore, it could be argued that gender may not be a determinant of interlanguage request strategy use. Moreover, since the situation to which the participants had to respond necessitated the use of indirect strategy, it might not be the case that female learners are pragmatically more competent than their fellow male learners, or in other words the pragmatic competence levels of the learners from the two gender groups, with the assumption that other things are equal, may be fundamentally the same.

Finally, a word in terminology may be in order here. The present study was situated within the realm of interlanguage pragmatics, defined as "the study of nonnative speakers' comprehension, production, and acquisition of linguistic action in L2 [second language]" (Kasper, 2010, p. 141). Admittedly, scholars working within the paradigm of ELF (English as a lingua franca) might feel uneasy with the concept of interlanguage, since the concept seems to be fused with the ideology that conceptualizes a language learner not as "a language user whose real-world interactions are deserving of unprejudiced description", but rather as "the possessor of incomplete or deficient communicative competence, putatively striving for the 'target' competence of an idealized 'native speaker'" (Firth, 1996, p. 241, italics in original). Leech (2014) astutely argued that

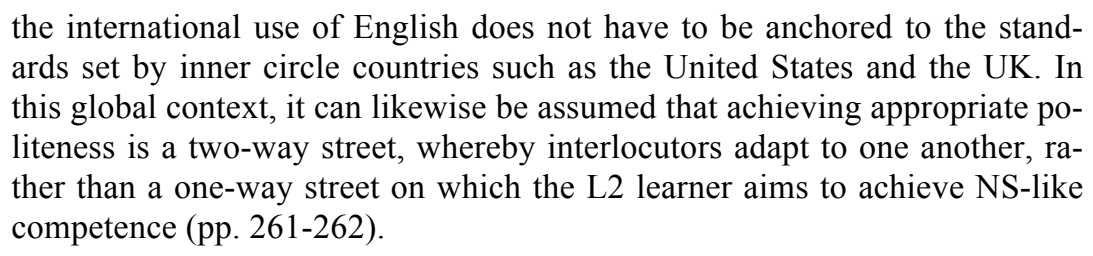
ards set by inner circle countries such as the United States and the UK. In this global context, it can likewise be assumed that achieving appropriate politeness is a two-way street, whereby interlocutors adapt to one another, rather than a one-way street on which the L2 learner aims to achieve NS-like competence (pp. 261-262).

In short, ELF scholars claim that the use of NS norm is problematic in pragmatic research involving NNS participants. While such argumentation sounds valid at least on paper, in reality, however, the so-called 'two-way-street' achievement may be difficult, if not impossible, to accomplish especially in status of unequal discursive situation, whereby the power of the NS is much higher than that of the NNS, as in the situation depicted in the scenario used in the present study (between a low-level staff and the big boss). In such a situation, using a pragmatic norm which does not conform to the pragmatic norm prevalent in the NS lingua culture might cause what is referred to as a 'sociopragmatic failure' (see Thomas, 1983), which in turn might lead to a catastrophic consequence on the part of the NNS, such as employment termination 
(see Murray, 2010). This fact largely motivated the use of NS norm in the present study. Moreover, the concept of interlanguage is pervasive in the field of interlanguage pragmatics, and is not considered problematic. Therefore, in keeping with the scholarly practice adopted in the field within which it is situated, the present study continuous to use the concept of pragmatics.

\section{CONCLUSIONS AND SUGGESTIONS}

The findings lead to the seemingly valid conclusion that pragmatic competence may not be determined by either grammatical competence or gender, either in isolation or in combination. This further carries the implication that grammatical and pragmatic competence appear to develop independently of each other (i.e. the development of pragmatic competence does not rely on the development of grammatical competence), or in other words they take different paths of development. In addition, it appears that female learners are not necessarily different than their male counterparts when it comes to using language appropriately in concrete situations. The findings showed that both male and female learners had to respond to the same situation wherein indirect request strategy was the default strategy.

Admittedly, the above conclusions should be treated with caution due to the small size of the sample of the present study. That relatively few participants involved $(\mathrm{N}=40)$ is apparently the major drawback of the present study. Moreover, the differential ratios of females and males to the total sample in the present study might also affect the validity of the findings, given that one of the aims of the study was to examine whether gender could significantly predict the use of indirect request strategy. Therefore, it is suggested that future studies should be conducted with a much larger sample size (perhaps more than 100) and the number of females and males involved should be (virtually) identical. In so doing, confidence in conclusions derived from statistical procedures could no doubt be greatly enhanced. Another apparent limitation of the present study is that it focused on only one speech act (i.e. request). In order to validate the conclusion made in this paper future studies might need to investigate the relationship between grammatical competence and a number of different speech acts or even other pragmatic aspects.

Putting aside the drawbacks of the present study, the findings pedagogically implies that development of pragmatic competence in a second or foreign language cannot be accelerated through grammar teaching. To put it in differ- 
ent terms, equipping learners with ability to use language according to social conventions might need a specific instructional treatment, a treatment that may be different from the instructional treatment needed to enable learners to use language grammatically accurately. Teachers hoping to improve learners' pragmatic competence might need to focus learners' attention more on pragmatic aspect of utterances than on their formal aspects. For example, a pragmatic consciousness-raising task where learners are exposed to speech situations and are asked to answer comprehension questions about language use might be used for this purpose. Meaning-based practice, rather than form-based practice, should also form a significant part of the instruction. It does not necessarily mean that discussion of formal aspects of utterances should be completely avoided. Rather, teachers' presentation of formal aspects should be kept to a minimum, and no less importantly, such presentation should be reactive, rather than proactive, in nature. Reactive form-focused instruction refers to brief instruction which occurs when learners make formal errors during meaning-focused activities (Ellis, 2001, pp. 23-24). Finally, the findings of the present study suggest that female and male EFL learners may not need different pedagogical intervention when it comes to teaching pragmatics since, other things being equal, learners coming from the two gender groups exhibit roughly the same level of pragmatic competence.

\section{REFERENCES}

Bardovi-Harlig, K. (2001). Evaluating the empirical evidence: Grounds for instruction in pragmatics. In K. R. Rose \& G. Kasper (Eds.), Pragmatics in language teaching (pp. 13-32). Cambridge: Cambridge University Press.

Bardovi-Harlig, K. (2010). Exploring the pragmatics of interlanguage pragmatics: Definition by design. In A. Trosborg (Ed.), Pragmatics across languages and cultures (pp. 219-259). Berlin: Walter de Gruyter.

Bardovi-Harlig, K. (2012). Pragmatics in second language acquisition. In S. M. Gass \& A. Mackey (Eds.), The Routledge handbook of second language acquisition (pp. 147-162). New York: Routledge.

Blum-Kulka, S., \& Olshtain, E. (1984). Requests and apologies: A crosscultural study of speech act realization patterns (CCSARP). Applied Linguistics, 5(3), 196-213. 
Brown, P., \& Levinson, S. C. (1987). Politeness: Some universals and language usage. Cambridge: Cambridge University Press.

Celaya, M. L., \& Barón, J. (2015). The interface between grammar and pragmatics in EFL measurement and development. European Journal of Applied Linguistics, 3(2), 181-203.

Celce-Murcia, M. (2007). Rethinking the role of communicative competence in language teaching. In E. Alcón Soler \& M. P. Safont Jordà (Eds.), Intercultural language use and language learning (pp. 41-57). Dordrecht, The Netherlands: Springer.

Chen, Y.-s. (2015a). Chinese learners' cognitive processes in writing email requests to faculty. System, 52, 51-62.

Chen, Y.-s. (2015b). Developing Chinese EFL learners' email literacy through requests to faculty. Journal of Pragmatics, 75, 131--149.

Chen, Y.-s. (2016). Understanding the development of Chinese EFL learners' email literacy through Exploratory Practice. Language Teaching Research, 20(2), 165-180.

Cohen, A. D. (2010). Coming to terms with pragmatics. In N. Ishihara \& A. D. Cohen (Eds.), Teaching and learning pragmatics: Where language and culture meet (pp. 3-20). Harlow: Pearson Education.

Drew, P., \& Couper-Kuhlen, E. (2014). Requesting - from speech act to recruitment. In P. Drew \& E. Couper-Kuhlen (Eds.), Requesting in social interaction (pp. 1-34). Amsterdam/ Philadelphia: John Benjamins.

Economidou-Kogetsidis, M. (2011). "Please answer me as soon as possible": Pragmatic failure in non-native speakers' e-mail requests to faculty. Journal of Pragmatics, 43, 3193-3215.

Ellis, R. (2001). Form-focused instruction and second language learning. Malden, MA: Blackwell.

Félix-Brasdefer, J. C. (2012). E-mail requests to faculty: E-politeness and internal modification. In M. Economidou-Kogetsidis \& H. Woodfield (Eds.), Interlanguage request modification (pp. 87-118). Amsterdam: John Benjamins.

Félix-Brasdefer, J. C., \& Cohen, A. D. (2012). Teaching pragmatics in the foreign language classroom: Grammar as a communicative resource. Hispania, 95(4), 650-669.

Field, A. (2009). Discovering statistics using SPSS (and sex and drugs and rock ' $n$ ' roll) (Third ed.). London: Sage Publication. 
Firth, A. (1996). The discursive accomplishment of normality": On 'lingua franca' English and conversation analysis. Journal of Pragmatics, 26, $237-$ 259.

Hahs-Vaughn, D. L. (2017). Applied multivariate statistical concepts. Abingdon: Routledge.

Jones, J. F., \& Adrefiza. (2017). Comparing apologies in Australian English and Bahasa Indonesia: Cultural and gender perspectives. Journal of Politeness Research, 13(1), 89-119.

Kasper, G. (2010). Interlanguage Pragmatics. In M. Fried, J.-O. Östman \& J. Verschueren (Eds.), Variation and change: Pragmatic perspectives (pp. 141-154). Amsterdam / Philadelphia: John Benjamins.

Kasper, G., \& Rose, K. R. (2002). Pragmatic development in a second language. Malden: Blackwell Publishing.

Kecskes, I. (2014). Intercultural pragmatics. New York: Oxford University Press.

Kecskes, I. (2015). How does pragmatic competence develop in bilinguals? International Journal of Multilingualism, 12(4), 419-434.

King, B. W., \& Holmes, J. (2014). Gender and pragmatics. In C. A. Chapelle (Ed.), The encyclopedia of applied linguistics (pp. 1-4). Malden, MA: John Wiley \& Sons.

Leech, G. N. (1983). Principles of pragmatics. Essex: Longman.

Leech, G. N. (2014). The pragmatics of politeness. New York: Oxford University Press.

Murray, N. (2010). Pragmatics, awareness raising, and the Cooperative Principle. ELT Journal, 64(3), 293-301.

Nguyen, T. T. M., Do, T. T. H., Nguyen, A. T., \& Pham, T. T. T. (2015). Teaching email requests in the academic context: A focus on the role of corrective feedback. Language Awareness, 24(2), 169-195.

Roever, C. (2011). Testing of second language pragmatics: Past and future. Language Testing, 28(4), 463-481.

Rose, K. R. (2013). Pragmalinguistics. In P. Robinson (Ed.), The Routledge encyclopedia of second language acquisition (pp. 499-500). New York: Routledge.

Schauer, G. A. (2009). Interlanguage pragmatic development: The study abroad context. New York: Continuum.

Schmidt, R. W. (1983). Interaction, acculturation, and the acquisition of communicative competence: A case study of an adult. In N. Wolfson \& E. 
Judd (Eds.), Sociolinguistics and language acquisition (pp. 137-174). Cambridge, MA: Newbury House.

Soler, E. A. (2013). Mitigating e-mail requests in teenagers' first and second language academic cyber-consultation. Multilingua, 32(6), 779-799.

Soler, E. A. (2015). Instruction and pragmatic change during study abroad email communication. Innovation in Language Learning and Teaching, 9(1), 34-45.

Szczepaniak-Kozak, A. (2016). Interlanguage pragmatics of EFL advanced learners: Insights from a longitudinal study into the development of the speech act of request in the Polish context. In M. Pawlak (Ed.), Classroom-oriented research: Reconciling theory and practice (pp. 197212). Basel, Switzerland: Springer.

Takahashi, S. (2013). Sociopragmatics. In P. Robinson (Ed.), The Routledge encyclopedia of second language acquisition (pp. 597-599). New York: Routledge.

Tavakoli, H. (2012). A dictionary of research methodology and statistics in applied linguistics. Tehran, Iran: Rahnama Press.

Thomas, J. (1983). Cross-cultural pragmatic failure. Applied Linguistics, 4(2), 91-112.

Timpe Laughlin, V., Wain, J., \& Schmidgall, J. (2015). Defining and operationalizing the construct of pragmatic competence: Review and recommendations. ETS Research Report No. RR-15-06. Princeton, NJ: Educational Testing Service.

Woodfield, H. (2015). Sociopragmatic variation in native speakers' and ESL learners' requests. In K. Beeching \& H. Woodfield (Eds.), Researching sociopragmatic variability: Perspectives from variational, interlanguage and contrastive pragmatics (pp. 151-173). Basingstoke: Palgrave Macmillan.

Zhu, W. (2012). Polite requestive strategies in emails: An investigation of pragmatic competence of Chinese EFL learners. RELC Journal, 43(2), 217 -238 . 
Sanjaya \& Sitawati, Interlanguage Request Strategy 235

\section{APPENDIX}

\section{Situation}

You are working for a multinational company. The manager of the company, Mr. James Blunder, is an American. He has asked you to send a parcel to another company located quite far away from where you work, so you need a car to deliver the parcel. You can drive, but do not have a car. The manager now is in the U.S. on a business trip. But his car is available for use. Before he left for the U.S., he said that if you needed something you can e-mail him at jblunder@gmail.com. 